Article

\title{
Electrorheological Characteristics of Poly(diphenylamine)/magnetite Composite-Based Suspension
}

\author{
Yu Zhen Dong ${ }^{\circledR}$ and Hyoung Jin Choi * \\ Department of Polymer Science and Engineering, Inha University, Incheon 22212, Korea \\ * Correspondence: hjchoi@inha.ac.kr; Tel.: +82-32-860-7486
}

Received: 20 August 2019; Accepted: 5 September 2019; Published: 9 September 2019

\begin{abstract}
Electro-responsive poly(diphenylamine)(PDPA)/ $\mathrm{Fe}_{3} \mathrm{O}_{4}$ composite particles were prepared by the synthesis of PDPA particles using a chemical oxidative polymerization technique followed by loading nano-sized $\mathrm{Fe}_{3} \mathrm{O}_{4}$ particles onto PDPA via a chemical co-precipitation process. The morphological image of the $\mathrm{PDPA} / \mathrm{Fe}_{3} \mathrm{O}_{4}$ particles was characterized by scanning electron microscope and transmission electron microscope. The crystalline structure was scrutinized by X-ray diffraction. The rheological characteristics of the suspension composed of PDPA/Fe $\mathrm{O}_{4}$ particles suspended in silicone oil were investigated by a rotation rheometer, demonstrating standard electrorheological (ER) characteristics with a dramatic increase in shear stress and dynamic moduli under the application of an electrical field strength. The shear stress curves under an electrical field could be described using the Bingham model and the yield stress showed a power-law relationship with the electric field strength with an exponent of 1.5, following the conduction model. Furthermore, the frequency-dependent dielectric behaviors of the PDPA/ $\mathrm{Fe}_{3} \mathrm{O}_{4}$ ER suspension was tested using an inductance (L)-capacitance (C)-resistance (R) (LCR) meter. The dielectric properties were well described using the Cole-Cole equation and were consistent with the results of the ER experiments.
\end{abstract}

Keywords: poly(diphenylamine); magnetite; composite; electrorheological

\section{Introduction}

Electrorheological (ER) fluids belong to a class of "smart" materials, which are generally suspension systems consisted of semiconducting or polarizable particles suspended in a continuous phase medium, primarily for anhydrous insulating liquids, such as silicone oils, mineral oils, etc. [1]. Their rheological properties exhibit dramatic and rapid changes from a liquid-like to a solid-like phase upon the application of external electrical fields. The mechanism for this phenomenon is still being explored, but the most accepted one is the polarization mechanism. As given in Scheme 1, while without an electrical field, the particles in the ER fluid disperse freely in the carrier liquid and assume a liquid-like state, with an input electrical field, the dipoles of the particles can be polarized instantly and arrange to make a chain-like form with the direction of the electrical field due to the induced electrostatic force among the particles [2-4]. Therefore, the ER suspension becomes a solid-like phase, exhibiting different rheological behaviors compared to a liquid-like ER suspension without an external electrical field. The changes in rheological properties include an increased shear viscosity, appearance of yield stress and increased dynamic modulus, where the ER fluid is similar to Bingham plastics [5,6]. In particular, chain-like structures are released as the electrical field is removed, allowing the ER suspension to recover to a liquid-like phase [7]. This tunable transition of ER fluids through the addition and removal of an external electrical field is believed to have a very large application potential in many industrial areas [8,9]. As ER fluids are developed continuously and the ER mechanism is understood more 
completely, in addition to being applicable to conventional components, such as dampers, brakes, switches, etc., ER fluids are gradually attracting attention in the fields of intelligent robotic systems, crude oil transportation, and food processing [10-12].

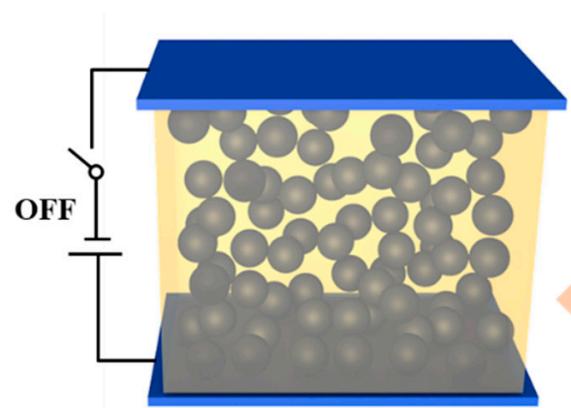

Liquid-like

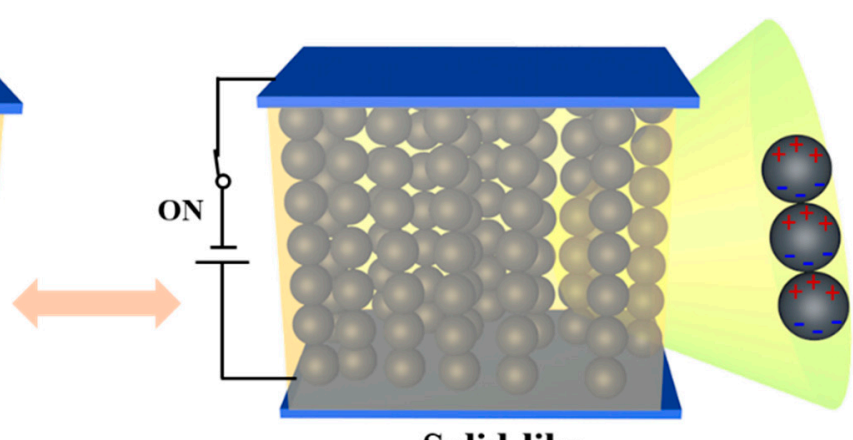

Solid-like

Scheme 1. Schematic diagram of transition between liquid-like and solid-like state for electrorheological (ER) fluid.

A range of materials, such as cellulose, starch, clay, oxide mineral, carbon-based materials (carbon nanotube, graphene oxide, etc.), conducting polymers, poly(ionic liquid) (PIL), etc. have been studied for the development of ER materials [13-19]. Compared to extrinsically polarizable materials that need to absorb water to activate ER effects, materials that are intrinsically polarizable or conducting are favored because of their better prospects in industry. Among them, the intrinsic conductive polymers have drawn extensive attention owing to their processability, low specific density, flexibility, etc. Most of these polymers are conjugated systems, and the $\pi$-bonded electrons in the polymer chain have low ionization potentials and high electron affinities. This causes the $\pi$-bonded electrons to easily escape from the orbit to form enough charge carriers, and the $\pi$-electron orbits overlap to form a conduction band to provide a channel for the movement of charge carriers, thereby making the polymer conducting. In particular, the conductivity of such conducting polymers can be controlled using a doping and de-doping process to suit different applications [20,21]. By taking an advantage of doping and de-doping, electrons can be added to the empty orbit of the polymer or the electrons can be pulled away from the occupied orbital. Therefore, the energy level of the original $\pi$-electron energy band is changed, resulting in a changed energy level difference between the energy bands. Consequently, the electrical conductivity can be changed. Conductivity too low usually leads to undesirable ER effects, and conductivity too high can easily cause short circuit problems, therefore a suitable conductivity is an important factor for its introduction as an ER material. Research on conducting polymers in the field of ER has also reported great achievements, such as polyaniline (PANI), polypyrrole, polyindole, poly(3,4-ethylenedioxythiophene), etc. [22-26]. Nonetheless, the electrical conductivity of these polymers in their pristine state is usually too high to be used directly as ER materials. Therefore, for use in ER fluids, these conducting polymers usually require an additional de-doping process.

As a type of conducting polymer, poly(diphenylamine) (PDPA) has also drawn attention owing to its electrochemistry, optical property, and higher solubility in organic solvents compared to PANI, and other conducting polymeric materials [27]. Moreover, the appropriate electrical conductivity of PDPA makes it suitable as an ER material because it does not require any de-doping process to prevent short circuits and is enough to generate sufficiently strong chain-like form with an input electrical field. Furthermore, recent research has shifted gradually to conducting polymer composites because they not only improve certain inherent limitations of polymers, but also enrich the properties of materials, such as chemical stability, mechanical properties, and thermal stability [28,29]. In particular, composite materials of conducting polymer and inorganic nanoparticles can impart special properties to the composites and enhance their application potential in many fields [30]. A wide range of this type of organic-inorganic composite material have been synthesized and adopted as excellent ER materials, 
including PANI/laponite [31], poly(3,4-ethylenedioxythiophene)/ $\mathrm{SiO}_{2}\left(\mathrm{PEDOT} / \mathrm{SiO}_{2}\right)$ [32], core-shell structured $\mathrm{Fe}_{3} \mathrm{O}_{4}$-polypyrrole $\left(\mathrm{Fe}_{3} \mathrm{O}_{4}\right.$-PPy) [33], $\mathrm{SiO}_{2} / \mathrm{PPy}$ [34], $\mathrm{Fe}_{2} \mathrm{O}_{3} / \mathrm{PANI}$ [35], $\mathrm{TiO}_{2} / \mathrm{PANI}$ [36,37], and $\mathrm{Fe}_{3} \mathrm{O}_{4} @ \mathrm{PANI}$ [38]. These materials exhibit excellent ER properties and yield stresses of up to several hundred Pa under an electric field. However, these materials all require the process of de-doping with either sodium hydroxide solution or aqueous ammonia solution before preparing the ER fluid. In contrast, one of the novelties of the materials prepared in this work was that it was expected to have suitable conductivity for their ER application without any de-doping process. Nano-sized $\mathrm{Fe}_{3} \mathrm{O}_{4}$ is often used as an inorganic component and is also used widely in chemistry, food, and medicine [39-41] because of its soft magnetic properties, biocompatibility, low cost, and easy preparation. In addition, it has been used as ER materials [42].

In this study, organic-inorganic PDPA/ $/ \mathrm{Fe}_{3} \mathrm{O}_{4}$ composite particles were synthesized by loading nano-sized $\mathrm{Fe}_{3} \mathrm{O}_{4}$ nanoparticles on a conducting PDPA matrix using a simple chemical co- precipitation method and adopted in an ER suspension. The behaviors of the PDPA/ $\mathrm{Fe}_{3} \mathrm{O}_{4}$ composite particles were characterized and then their ER properties when suspended in silicone were investigated.

\section{Materials and Experimental Methods}

\subsection{Materials}

Diphenylamine (DPA) (Sigma-Aldrich, St. Louis, MO, USA), ammonium persulfate (APS) (Daejung Chem., Siheung, Korea) and hydrochloric acid ( $\mathrm{HCl}$ ) (Junsei Chem., Tokyo, Japan) were used for the synthesis of PDPA first. In the process of loading $\mathrm{Fe}_{3} \mathrm{O}_{4}$ on PDPA, ferric chloride hexahydrate $\left(\mathrm{FeCl}_{3} \cdot 6 \mathrm{H}_{2} \mathrm{O}\right)$ (Sigma-Aldrich, St. Louis, MO, USA), ferrous sulfate heptahydrate $\left(\mathrm{FeSO}_{4} \cdot 7 \mathrm{H}_{2} \mathrm{O}\right)$ (Sigma-Aldrich, St. Louis, MO, USA), and ammonia solution $\left(\mathrm{NH}_{4} \cdot \mathrm{OH}, \mathrm{NH}_{3}: 28-30 \%(\mathrm{~mol} / \mathrm{mol})\right.$ (Junsei Chem., Tokyo, Japan) were used. Ethanol (Samchun Chem., Pyeongtaek, Korea) and distilled water were adopted as solvents. The continuous phase of the ER suspension was silicone oil ( $50 \mathrm{cSt}$, Shin-Etsu, Tokyo, Japan).

\subsection{Synthesis of PDPA}

At first, PDPA particles were fabricated through a chemical oxidative polymerization process, as proposed in the previous study [43]. DPA $(6.0 \mathrm{~g})$ monomer was dissolved in ethanol $(150 \mathrm{~mL})$ with intensive magnetic stirring for a few minutes to obtain a homogeneous solution and it was then transferred to a three-neck glass reactor $(500 \mathrm{~mL})$. Once an aqueous $\mathrm{HCl}$ solution $(3 \mathrm{M}, 120 \mathrm{~mL})$ was input, the reaction mixture was maintained at $5{ }^{\circ} \mathrm{C}$ by a refrigerated bath under stirring. Concurrently, a solution of APS $(3.01 \mathrm{~g})$ dissolved in the aqueous $\mathrm{HCl}(3 \mathrm{M}, 15 \mathrm{~mL})$ was added dropwise to the reaction mixture. The resulting reaction mixture was stirred continuously for an additional $16 \mathrm{~h}$. The product particles were separated and cleaned several times with ethanol and distilled water using a centrifuge. The precipitate was dried completely in a vacuum oven $\left(60^{\circ} \mathrm{C}\right.$ for $\left.12 \mathrm{~h}\right)$.

\subsection{Synthesis of PDPA/Fe $\mathrm{O}_{4}$}

The PDPA $/ \mathrm{Fe}_{3} \mathrm{O}_{4}$ composite nanoparticles were then prepared by loading magnetite on PDPA via a chemical co-precipitation process. PDPA ( $1 \mathrm{~g})$ was suspended in a $50 \%$ aqueous solution of ethanol and mixed with $40 \mathrm{~mL}$ of an aqueous solution $\left(0.5 \mathrm{M} \mathrm{FeCl}_{3}\right.$ and $0.25 \mathrm{M}$ of $\left.\mathrm{FeSO}_{4}\right)$. After heating the mixed solution to $60^{\circ} \mathrm{C}, 10 \mathrm{~mL}$ of aqueous $\mathrm{NH}_{3}$ solution was added, and the reaction was continued for $2 \mathrm{~h}$. The precipitated product was collected by magnetic separation and then cleaned several times with ethanol and dried completely at $60^{\circ} \mathrm{C}$ for $12 \mathrm{~h}$. Scheme 2 presents a schematic diagram of the synthetic route of the PDPA $/ \mathrm{Fe}_{3} \mathrm{O}_{4}$ composite.

\subsection{Characterization}

The density of the PDPA/Fe $\mathrm{O}_{4}$ particles tested via a gas pycnometer (AccuPyc 1330, Micromeritics Instrument Corp., Norcross, GA, USA) was $2.44 \mathrm{~g} / \mathrm{cm}^{3}$, while the electrical conductivity was obtained 
to be $5.9 \times 10^{-8} \mathrm{~S} / \mathrm{cm}$ via a low resistivity meter (Loresta-GP MCP-T610, Mitsubishi Chem., Tokyo, Japan) and a square probe (electrode distance: $1.5 \mathrm{~mm}$ ) (MCP-TPQPP, Mitsubishi Chem., Tokyo, Japan). For the measurement, the PDPA powder was pressed into a disk with a diameter of $13 \mathrm{~mm}$. The PDPA $/ \mathrm{Fe}_{3} \mathrm{O}_{4}$ ER suspension was prepared by suspending PDPA/ $/ \mathrm{Fe}_{3} \mathrm{O}_{4}$ (particle concentration of $10 \mathrm{vol} \%)$ in silicone oil.

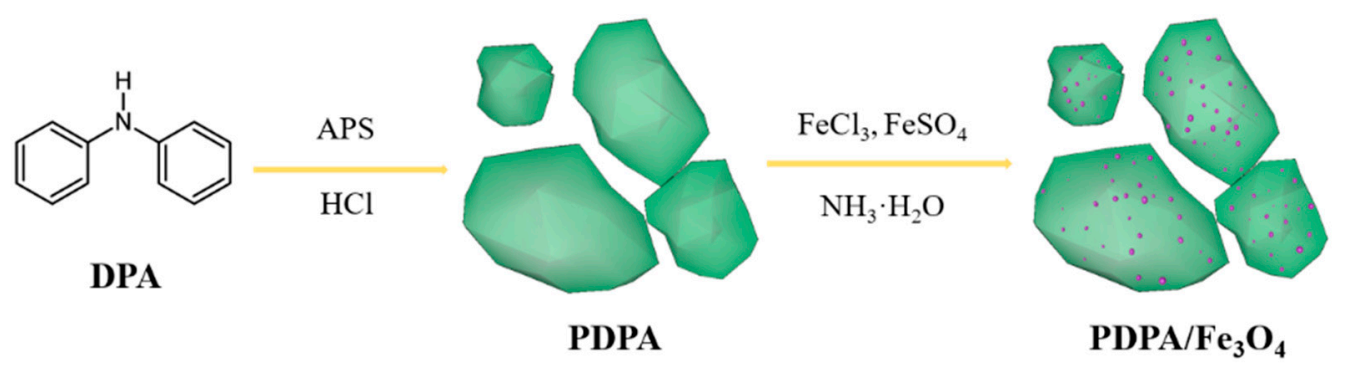

Scheme 2. Synthetic route of poly(diphenylamine)(PDPA)/ $\mathrm{Fe}_{3} \mathrm{O}_{4}$ composite.

\section{Results and Discussion}

\subsection{Characterization of Synthesized Materials}

Morphological images of PDPA and PDPA $/ \mathrm{Fe}_{3} \mathrm{O}_{4}$ were investigated via a scanning electron microscope (SEM) (SU-8010, Hitachi, Tokyo, Japan) by adhering the powder to the sample holder with a double-sided carbon tape. As shown in Figure 1a, PDPA showed irregular shapes with a size distribution ranging from approximately 0.3 microns to a few microns. Simultaneously, the particle size distribution of PDPA (Figure 1e) measured by the laser light scattering on a Malvern particle analyzer (Malvern Mastersizer 2000, Malvern Instruments, Worcestershire, UK) also showed that the smallest particle size was about 0.3 microns and the surfaced weighted mean diameter $(D[3,2])$ was 4.05 microns. Of the particles $50 \%$ were less than 8.54 microns, while particles over a few tens of microns are believed to be due to incompletely dispersed PDPA agglomerates, similar to the fact that large particles were not observed in the SEM image. The insets in Figure 1a,b showed partial enlargements of the surface of the PDPA and PDPA/ $/ \mathrm{Fe}_{3} \mathrm{O}_{4}$ composite, respectively. The surface of PDPA $/ \mathrm{Fe}_{3} \mathrm{O}_{4}$ was rougher than PDPA and spherical nanoparticles can be observed clearly. In order to further determine the morphology and structure of the materials, both PDPA and PDPA $/ \mathrm{Fe}_{3} \mathrm{O}_{4}$ powders were dispersed in water by sonication, and then their dispersions were added dropwise on a copper mesh, sufficiently dried, and observed by a transmission electron microscope (TEM) (CM-220, Phillips, Amsterdam, The Netherlands). Figure 1c,d present the TEM images of the PDPA and $\mathrm{PDPA} / \mathrm{Fe}_{3} \mathrm{O}_{4}$ composites, respectively, and the insets show the partial enlargements. Many spherical particles with diameters between 10 and $20 \mathrm{~nm}$ in enlargement of the PDPA/ $\mathrm{Fe}_{3} \mathrm{O}_{4}$ can be seen clearly. The $\mathrm{Fe}_{3} \mathrm{O}_{4}$ granules on the surface of PDPA can increase the roughness and specific surface area, which is believed to contribute to an enhanced ER effect. 

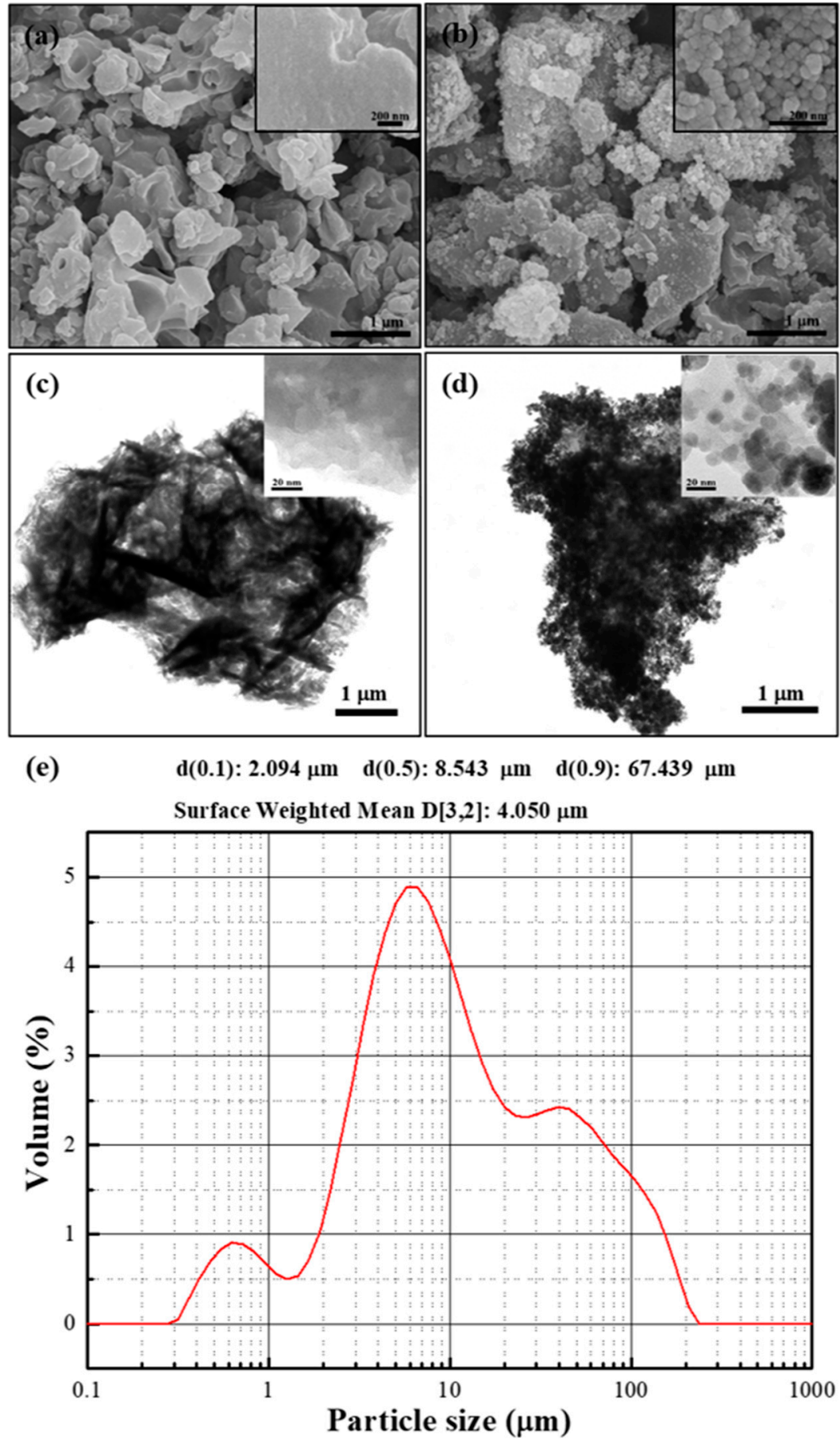

Figure 1. (a,b) SEM, (c,d) TEM images of PDPA and PDPA/Fe $\mathrm{O}_{3}$, and (e) particle size distribution of PDPA. (The inset shows partial enlargement).

Powder X-ray diffraction (XRD) (DMAX-2500, HORIBA, Kyoto, Japan) test of the PDPA and $\mathrm{PDPA} / \mathrm{Fe}_{3} \mathrm{O}_{4}$ composite was performed from $5^{\circ}$ to $90^{\circ} 2 \theta$ using $\mathrm{Cu}-\mathrm{K} \alpha$. Figure 2 presents the $\mathrm{XRD}$ data of both as-synthesized PDPA and PDPA/ $\mathrm{Fe}_{3} \mathrm{O}_{4}$ composite. Two distinct XRD peaks at approximately $18^{\circ}$ and $21^{\circ} 2 \theta$ for PDPA, and there was no XRD peak in the range of $40^{\circ}$ to $90^{\circ} 2 \theta$. The pattern of the PDPA $/ \mathrm{Fe}_{3} \mathrm{O}_{4}$ composite showed corresponding peaks for the (220), (311), (400), (422), (511), and (440) planes, which match with the cubic spinel crystal structure for $\mathrm{Fe}_{3} \mathrm{O}_{4}$ (JCPDS Card. No. 88-0315). The crystallite size (D) of $\mathrm{Fe}_{3} \mathrm{O}_{4}$ was determined from the following Scherrer equation [44]: 


$$
D=\frac{k \lambda}{\beta \cos \theta}
$$

where $k$ is a constant value of $0.89 ; \lambda$ is the radiation wavelength $(1.54184 \AA$ for $\mathrm{Cu}-\mathrm{K} \alpha)$; $\beta$ is the full width at half maximum (FWHM) of the XRD peak in radian, which is equal to $0.5^{\circ}$ ( $\pi / 360$ radians) at the highest intense peak at (311); $\theta$ is the Bragg diffraction angle, and the value at the highest intense peak was $17.77^{\circ}(17.77 \pi / 180$ radians). Therefore, the crystallite size was calculated to be $16.51 \mathrm{~nm}$. XRD of the composite revealed not only the characteristic peaks of the $\mathrm{Fe}_{3} \mathrm{O}_{4}$, but also the peaks of PDPA at approximately $20^{\circ}$.

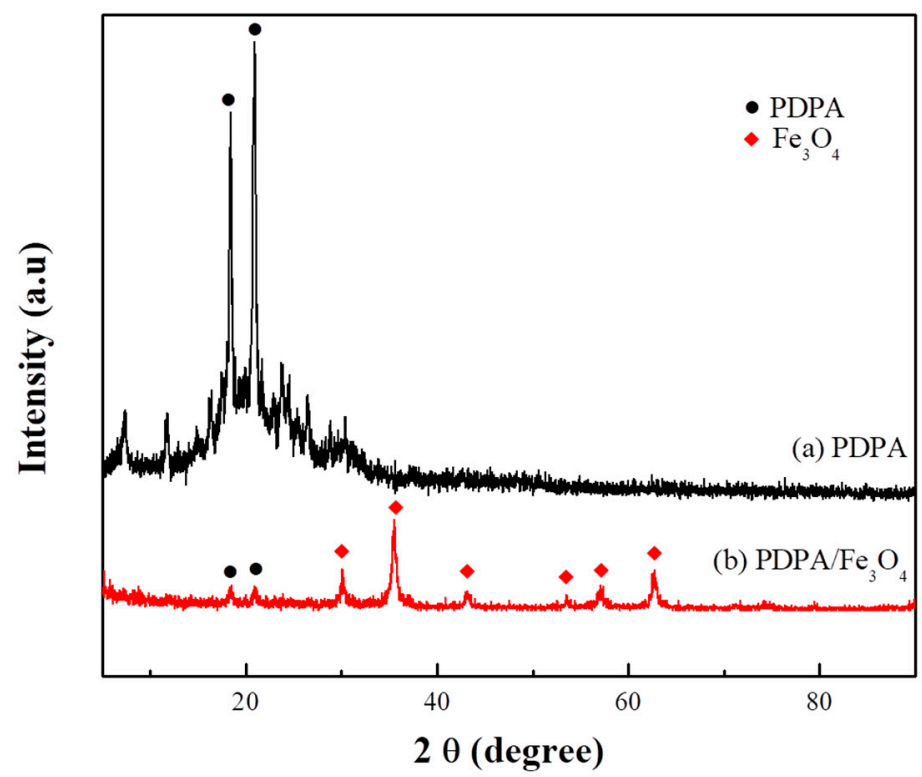

Figure 2. XRD spectra of (a) PDPA and (b) PDPA/ $/ \mathrm{Fe}_{3} \mathrm{O}_{4}$.

\subsection{Electrorheological Effect}

\subsubsection{Formation of Chain-Like Structures}

Optical microscopy (OM) was used to observe the transition of the suspension state for PDPA/Fe $\mathrm{O}_{3}$ nanoparticles in silicone oil under an electrical field. Figure 3 a shows the PDPA/ $\mathrm{Fe}_{3} \mathrm{O}_{4}$ nanoparticles dispersed without an electrical field, in which the nanoparticles were dispersed freely in the oil. When an electrical field was applied (Figure 3b), however, dipole changes of the particles formed, and particles arranged into chain-like structures in an electrical field direction due to electrostatic attractive forces between neighboring particles. In addition, during the direct observation with the OM, it was found that at the moment of the application of an electric field strength, the originally dispersed particles began to move rapidly to form a chain structure and reached a stable state within a few seconds, and over time, adjacent chain structures tended to gather together to form a chain with certain thickness. This may be because the direction of the dipoles was not completely coincident with the direction of the electric field, and the dipole interaction perpendicular to the direction of the electric field caused the aggregation of adjacent chains, however, this phenomenon may increase the strength of the chain structure. Furthermore, it can be also noted that even though a dynamic time-dependent evolution of the chain structure under applying the electric field is considered to be important for understanding the ER mechanism, this work has been seldom examined either via theoretically [45] or experimentally $[46,47]$. No direct observation has been performed.

Because of the formation of chain-like structures, the ER fluid can transform to a solid-like state from an initial fluid-like state by applying an external electrical field. Therefore, with an input electrical field, the ER suspension can exhibit obvious yield stress at a low shear rate range and shear-thinning 
behaviors of shear viscosity under a shear flow with a direction perpendicular to the electrical field, which can be corroborated in the following ER tests.
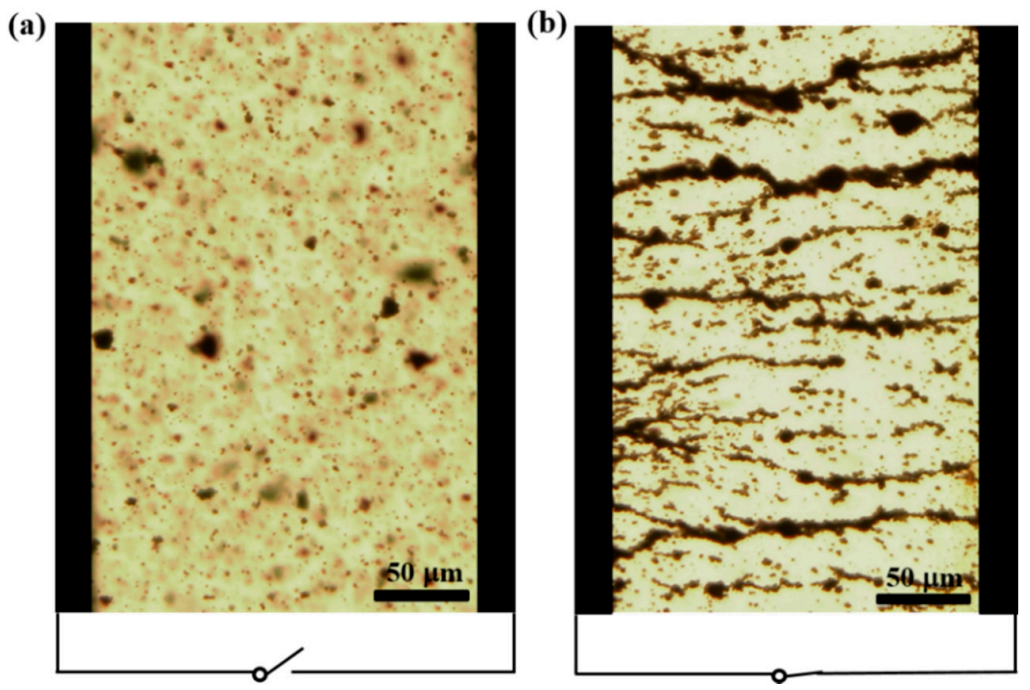

Figure 3. Optical microscopy $(\mathrm{OM})$ images of $\mathrm{PDPA} / \mathrm{Fe}_{3} \mathrm{O}_{4}$ particles suspended in silicone oil without (a), and with (b) the electric field $(0.75 \mathrm{kV} / \mathrm{mm})$.

\subsubsection{Steady Shear Tests}

The ER characteristics for the PDPA/ $\mathrm{Fe}_{3} \mathrm{O}_{4}$ composite ER suspension were investigated by a rotational rheometer (MCR 300, Anton Paar, Graz, Austria) with a cylindrical Couette-type geometry (CC17/E) of $0.71 \mathrm{~mm}$ gap distance. To investigate the ER properties in the presence of electrical field, a DC voltage generator was attached to the rheometer. Steady shear tests were measured using a controlled shear rate (CSR) mode with a shear rate ranging from $10^{-1}$ to $10^{3} 1 / \mathrm{s}$ at room temperature. Figure 4 shows both shear stress (Figure $4 a$ ) and viscosity (Figure $4 \mathrm{~b}$ ) as a function of shear rate with an input electric field $(0-2.0 \mathrm{kV} / \mathrm{mm})$. Without an electric field, the shear stress presented an approximately linear relationship with the shear rate, indicating a similar trend to that of a Newtonian fluid [48]. On the other hand, under an electrical field, the shear stress increased significantly and showed a plateau region in a low shear rate range, which is consistent with Bingham fluid characteristics [5,49]. Here, the particles were being polarized under the action of an electrical field, and an electrostatic force was generated to cause the particles to build a chain-like structure following the electrical field direction, thereby changing the ER suspension from a fluid-like to a solid-like phase. Under shear flow, when an electrical field was applied, competition between the hydrodynamic and electrostatic force in the ER suspension occurred. At the low shear rate range, the electrostatic force was predominant, and the deformation or damage to the chain structure caused by the shear flow could be recovered in time. As the shear rate increased, the electrostatic force gradually failed to recover the chain structure in time, and the particles begun to flow. The dynamic yield stress is known to be a minimum shear stress, in which the chain structure starts to be destroyed and the suspension can flow with shear flow. When the shear rate is sufficiently large, the hydrodynamic force becomes significant. The chain-like structures were almost completely broken and could not be recombined, where the ER suspension exhibited a similar property to a Newtonian fluid when the shear rate became larger than $100(1 / \mathrm{s})$, as shown in Figure 4a.

Figure $4 \mathrm{~b}$ presents shear viscosity curves. Without an input electrical field, the sample fluid exhibited weak shear-thinning characteristics, and as the shear rate increased, it gradually approached Newtonian fluid features. Under an input electrical field, however, the shear viscosity increased by hundreds to thousands of times compared to that without an electrical field, and exhibited significant shear-thinning as the shear rate increased. 
Furthermore, as presented in Figure 4a, the shear stress curves under an electrical field can be described using Bingham fluid model [50], which can be represented as

$$
\begin{gathered}
\tau_{s}=\tau_{d y}+\eta_{\infty} \dot{\gamma}, \tau_{s} \geq \tau_{d y} \\
\dot{\gamma}=0, \tau_{s}<\tau_{d y}
\end{gathered}
$$

where $\tau_{s}$ is the shear rate dependent shear stress; $\gamma$ is the shear rate; $\eta_{\infty}$ is the plastic viscosity; $\tau_{d y}$ is the dynamic yield stress, which generally shows a power-law relationship with an electrical field strength. Table 1 lists the fitted parameters of the Bingham fluid equation for the PDPA/ $\mathrm{Fe}_{3} \mathrm{O}_{4}$ ER fluid. Note that pure PDPA was also reported to be an ER material [43], and compared with a PDPA-based ER fluid, the PDPA/ $/ \mathrm{Fe}_{3} \mathrm{O}_{4}$-based ER suspension showed a more stable shear stress in the low shear rate range $(<101 / \mathrm{s})$, whereas the former showed reduced shear stress as the shear rate increased. Meanwhile, the electric field limit of PDPA/ $\mathrm{Fe}_{3} \mathrm{O}_{4}$-based ER fluid that can be applied is $2.0 \mathrm{kV} / \mathrm{mm}$, which is lower than that of the PDPA-based ER suspension $(2.5 \mathrm{kV} / \mathrm{mm})$. This is because the electrical conductivity of PDPA $/ \mathrm{Fe}_{3} \mathrm{O}_{4}\left(5.9 \times 10^{-8} \mathrm{~S} / \mathrm{cm}\right)$ was higher than that of PDPA $\left(8.913 \times 10^{-11} \mathrm{~S} / \mathrm{cm}\right)$, and its particle concentration prepared at $10 \mathrm{vol} \%$ was larger than that of the PDPA ER fluid (5 vol\%).
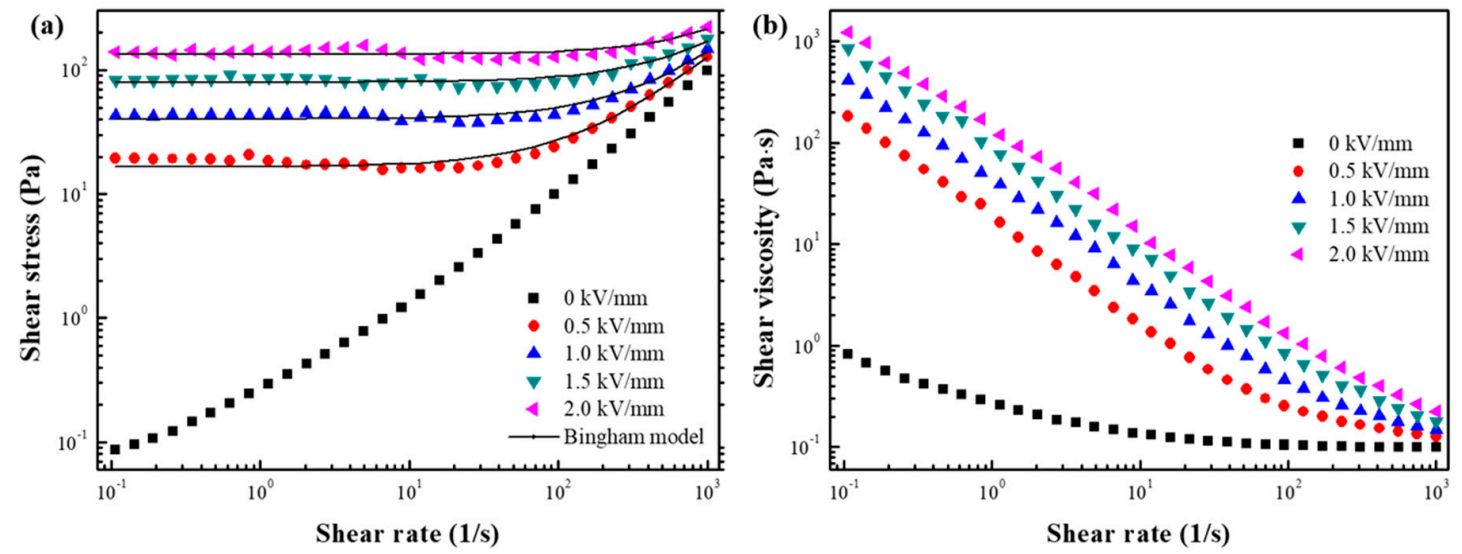

Figure 4. Shear rate-dependent (a) shear stress and (b) shear viscosity curves of PDPA/Fe $3 \mathrm{O}_{4}$-based ER fluid (10 vol\%, $50 \mathrm{cSt}$ silicone oil) under different electric field strengths.

Table 1. Fitted parameters of Bingham model for PDPA/ $\mathrm{Fe}_{3} \mathrm{O}_{4}$-based ER fluid ( $10 \mathrm{vol} \%, 50 \mathrm{cSt}$ silicone oil).

\begin{tabular}{ccc}
\hline Electric Field (kV/mm) & $\tau_{d y}$ & $\eta_{\infty}$ \\
\hline 0.5 & 16.6 & 0.11 \\
1.0 & 40.2 & 0.10 \\
1.5 & 79.9 & 0.09 \\
2.0 & 133.7 & 0.08 \\
\hline
\end{tabular}

Furthermore, to evaluate its ER effect, the ER efficiency $(e)$ was calculated using the shear viscosity at a specific electric field using the following equation:

$$
e=\frac{\eta_{E}-\eta_{0}}{\eta_{0}} \times 100 \%
$$

where $\eta_{E}$ and $\eta_{0}$ represent the shear viscosity at an input electrical field strength of $E$ and zero-field, respectively. As given in Figure 5, the ER efficiency increased with an increased shear rate, and the value was approximately $10^{6 \%}$ at an electrical field strength of $2.0 \mathrm{kV} / \mathrm{mm}$, which indicates that the PDPA $/ \mathrm{Fe}_{3} \mathrm{O}_{4}$ particles formed strong chain structures with an input electrical field. Meanwhile, 
as the shear rate increased, the chain structures were gradually destroyed and the ER efficiency was reduced continuously.

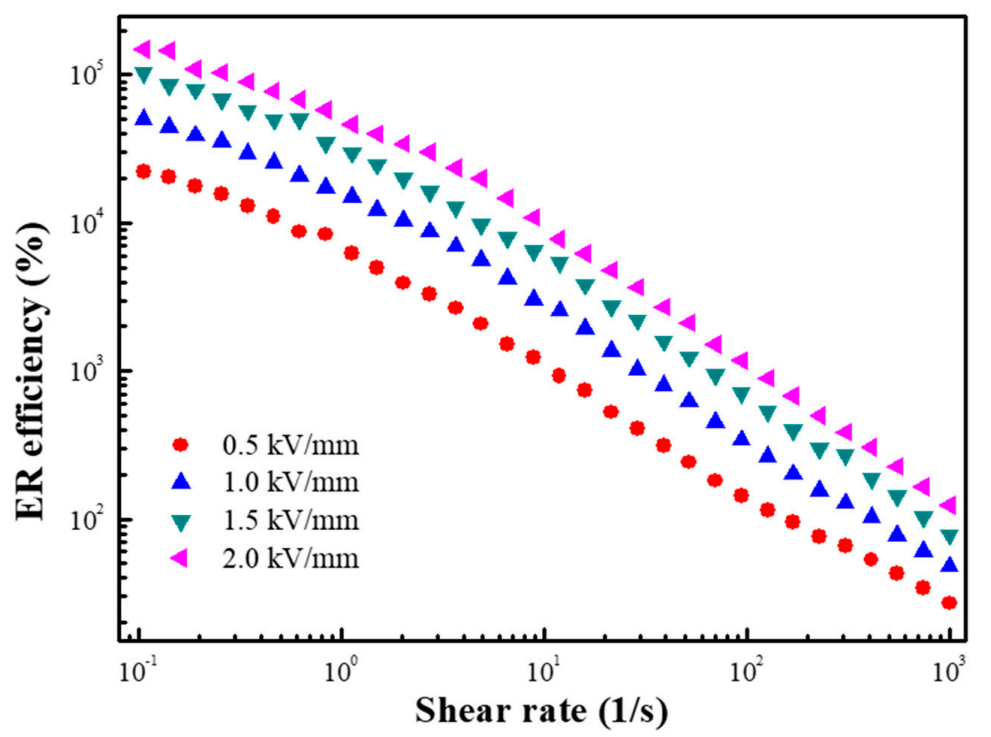

Figure 5. Shear rate-dependent ER efficiency of PDPA/ $\mathrm{Fe}_{3} \mathrm{O}_{4}$-based ER fluid (10 vol\%, 50 cSt silicone oil) under different electric field strengths.

\subsubsection{Dynamic Oscillation Test}

Oscillation tests were also carried out in a controlled shear deformation mode. Initially, the strain amplitude sweep tests were measured with a constant angular frequency $(6.28 \mathrm{rad} / \mathrm{s})$ to search the linear viscoelastic (LVE) region [51]. Figure 6 presents the strain-dependent storage $\left(G^{\prime}\right)$ and loss $\left(G^{\prime \prime}\right)$ moduli of the $\mathrm{PDPA} / \mathrm{Fe}_{3} \mathrm{O}_{4}$ ER suspension. In the low strain range, $G^{\prime}$ showed a plateau region, called the LVE region, where the chain-like forms were strong enough not to be destroyed by the applied strain. When the strain exceeded the critical value, structures that had formed began to be destroyed, showing a sharp decline in $G^{\prime}$. Therefore, to avoid excessive strain causing chain damage and affecting the frequency-dependent changes in the chain structures, a strain value of $0.007 \%$ in the LVE region was selected as constant strain in the following frequency sweep tests.

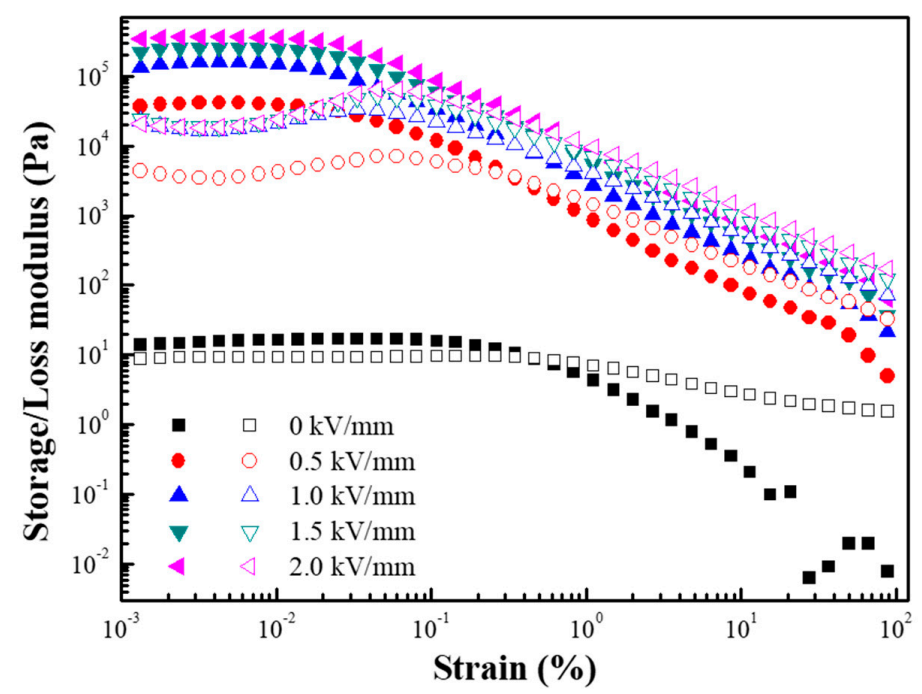

Figure 6. Storage $\left(G^{\prime}\right.$, closed symbols) and loss ( $G^{\prime \prime}$, open symbols) moduli as a function of strain for $\mathrm{PDPA} / \mathrm{Fe}_{3} \mathrm{O}_{4}$-based ER fluid (10 vol\%, $50 \mathrm{cSt}$ silicone oil) with constant angular frequency of $6.28 \mathrm{rad} / \mathrm{s}$. 
The elastic stress $\left(\tau_{e}\right)$ from the dynamic oscillation test can be calculated using Equation (5):

$$
\tau_{e}=G^{\prime} \cdot \gamma
$$

where $\gamma$ is the strain value. As given in Figure 7, at the low strain range, the elastic stress increased with increased shear strain, where the deformation of the chain structures could be restored after the stress was removed, indicating that the chain structures were elastic within this range. However, when the strain exceeded a critical value, the elastic stress showed a short plateau region and then decreased with increasing strain. The point at which the elastic stress showed the maximum value is defined as the yield point, and the elastic stress at this value is known to be the elastic yield stress $[52,53]$. The red circles in Figure 7 indicate the yield points.

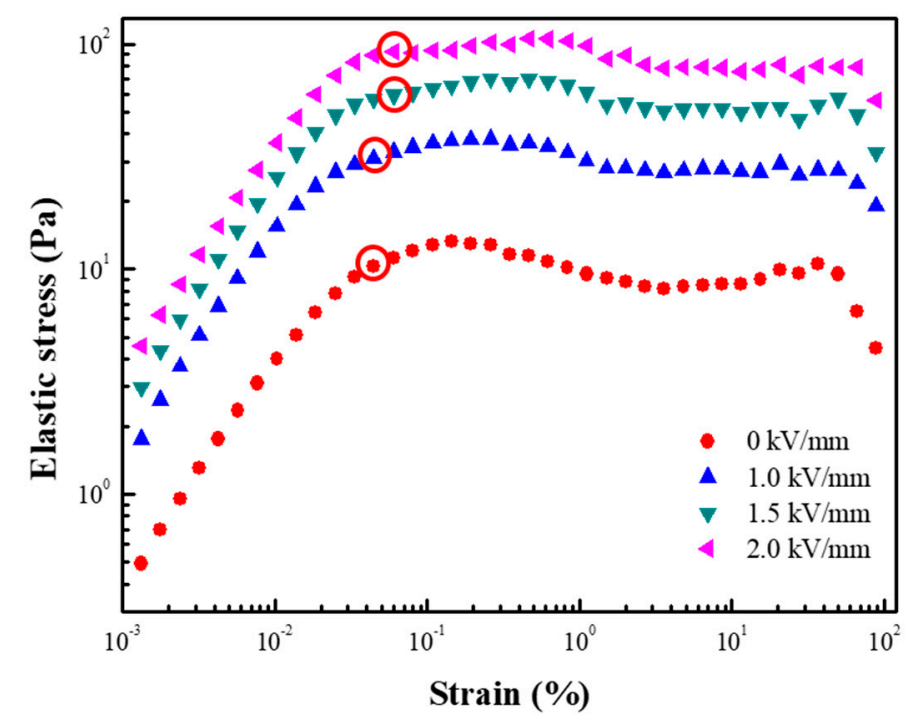

Figure 7. Elastic stress as a function of strain for PDPA/ $\mathrm{Fe}_{3} \mathrm{O}_{4}$-based ER fluid (10 vol\%, 50 cSt silicone oil). The red circles indicate the yield points.

The static yield stress $\left(\tau_{s y}\right)$ is defined as the minimum shear stress that causes the chain structures to begin to slide [54], which is different from the dynamic yield stress (i.e., the minimum stress that is required to continuously break the chain structures). Figure 8 demonstrates the dependence of shear viscosity on shear stress measured in a controlled shear stress (CSS) test mode where the shear stress exhibits a sudden decrease in shear viscosity when it reaches a certain value. The shear stress value at this point is regarded as $\tau_{s y}$. 


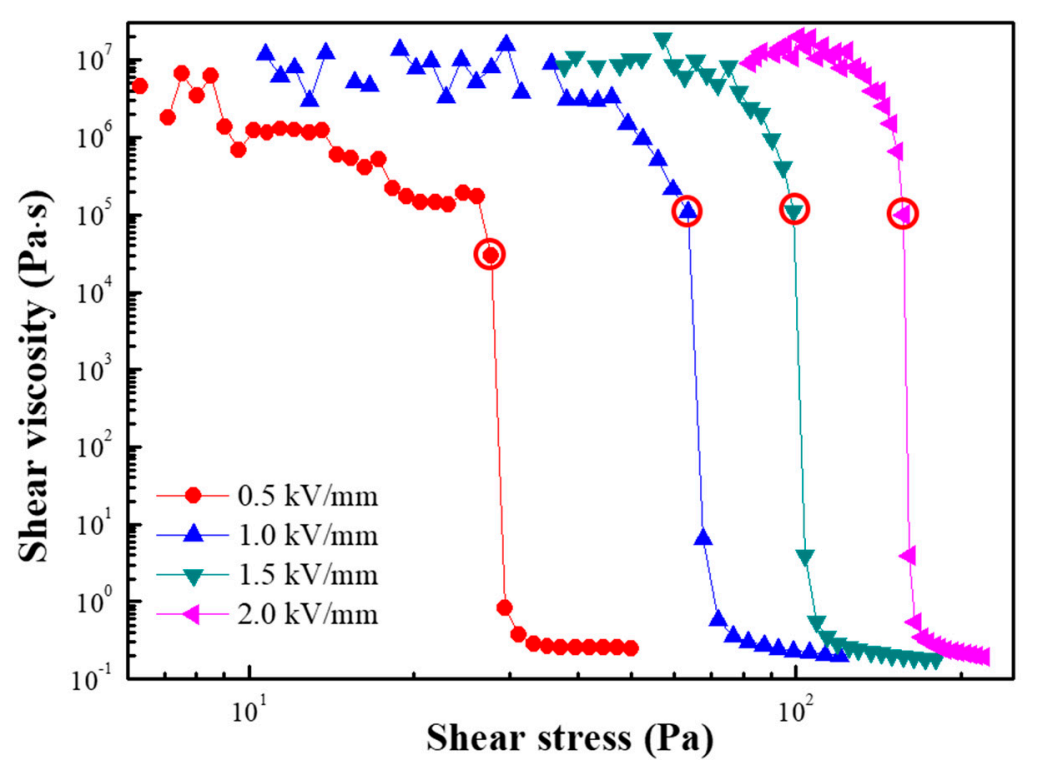

Figure 8. Shear stress-dependent shear viscosity of PDPA/ $\mathrm{Fe}_{3} \mathrm{O}_{4}$-based ER fluid $(10 \mathrm{vol} \%, 50 \mathrm{cSt}$ silicone oil). The red circles label the static yield stress.

Figure 9 presents the yield stress as a function of an input electric field, where Figure 7, Table 1, and Figure 8 show the elastic, dynamic, and static yield stresses, respectively. The correlation between the three types of yield stress and electrical field strength $(E)$ generally follows a power-law expression:

$$
\tau_{y} \propto E_{m}
$$

where the power law index, $m$, varies typically between 1.0 and 2.0, depending on the concentration of the ER fluids, morphology, size, dielectric, and conductivity of the different ER materials [15]. For the $\mathrm{PDPA} / \mathrm{Fe}_{3} \mathrm{O}_{4}$ ER suspension in this work, the slope was observed to be $m=1.5$ for all three different yield stresses, conforming to the conduction model proposed by Davis and Ginder [55], where the yield stress of an ER suspension is expressed proportional to the $E^{3 / 2}$.

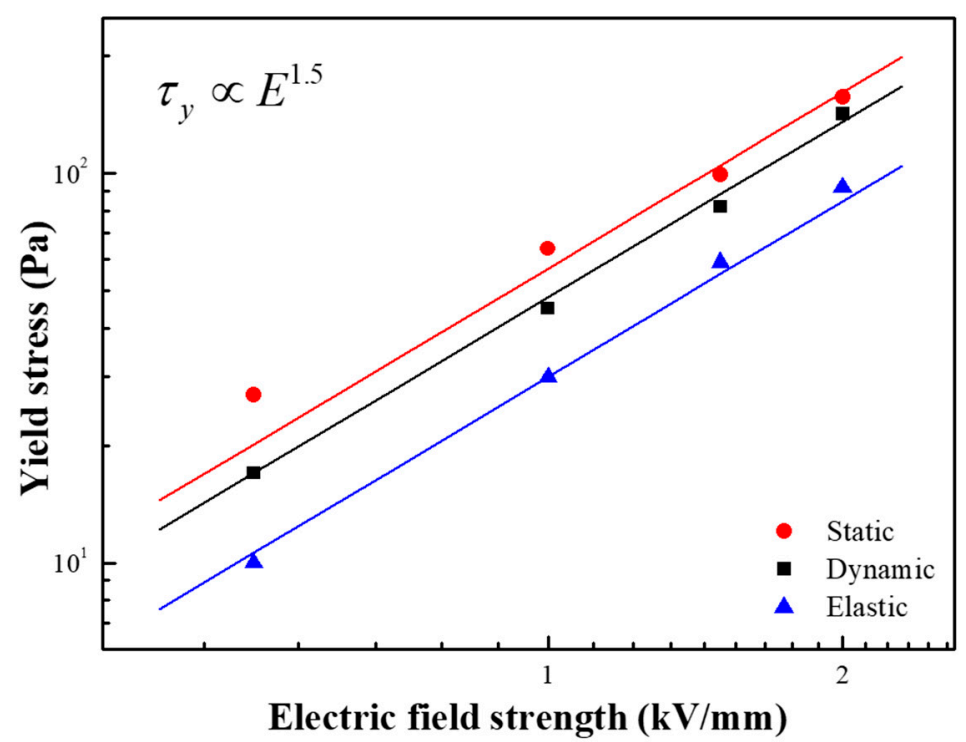

Figure 9. Elastic, dynamic, and static yield stress under various electric field strengths for PDPA/ $\mathrm{Fe}_{3} \mathrm{O}_{4}$-based ER fluid (10 vol\%, 50 cSt silicone oil). 
The frequency sweep measurement was tested with an angular frequency, varying from 0.1 and $200 \mathrm{rad} / \mathrm{s}$ at a constant strain $(0.007 \%)$. As given in Figure 10, without an electrical field, both $G^{\prime}$ and $G^{\prime \prime}$ increased with an increased angular frequency, but with an input electrical field, they exhibited a relatively stable value over a whole frequency region and increased with increasing electric field strength. This indicated that under an input electric field, the interactions between the particles became stronger and the chain structures were not easily broken. Furthermore, a time-dependent relaxation modulus $G(t)$ can be estimated from the frequency sweep test using the following Schwarzl equation [56]:

$$
G(t) \cong G^{\prime}(\omega)-0.566 G^{\prime \prime}(0.5 \omega)+0.203 G^{\prime \prime}(\omega) .
$$

Figure 11 presents the time-dependent relaxation modulus under different electrical field strengths. In the absence of electric field, $G(t)$ decreased significantly in a very short period of time, indicating that the ER suspension exhibited liquid-like properties. Meanwhile, with an electrical field, the relaxation modulus exhibited a stable value, showing that the ER fluid became a solid-like state.

In summary, it is not difficult to confirm that the PDPA/Fe $\mathrm{O}_{4}$-based ER fluid changes from a fluid-like state to a solid-like state under the stimulation of an electric field based on the results of the static shear tests and the dynamic oscillation tests. Moreover, under the electric field, with the increase of the shear rate, the ER fluid exhibited a very stable shear stress curve, such that the yield stress was up to $100 \mathrm{~Pa}$, and the ER efficiency was also very high. The relatively high and stable behaviors of $\mathrm{PDPA} / \mathrm{Fe}_{3} \mathrm{O}_{4}$-based ER fluid may increase the possibility of its practical application in engineering.

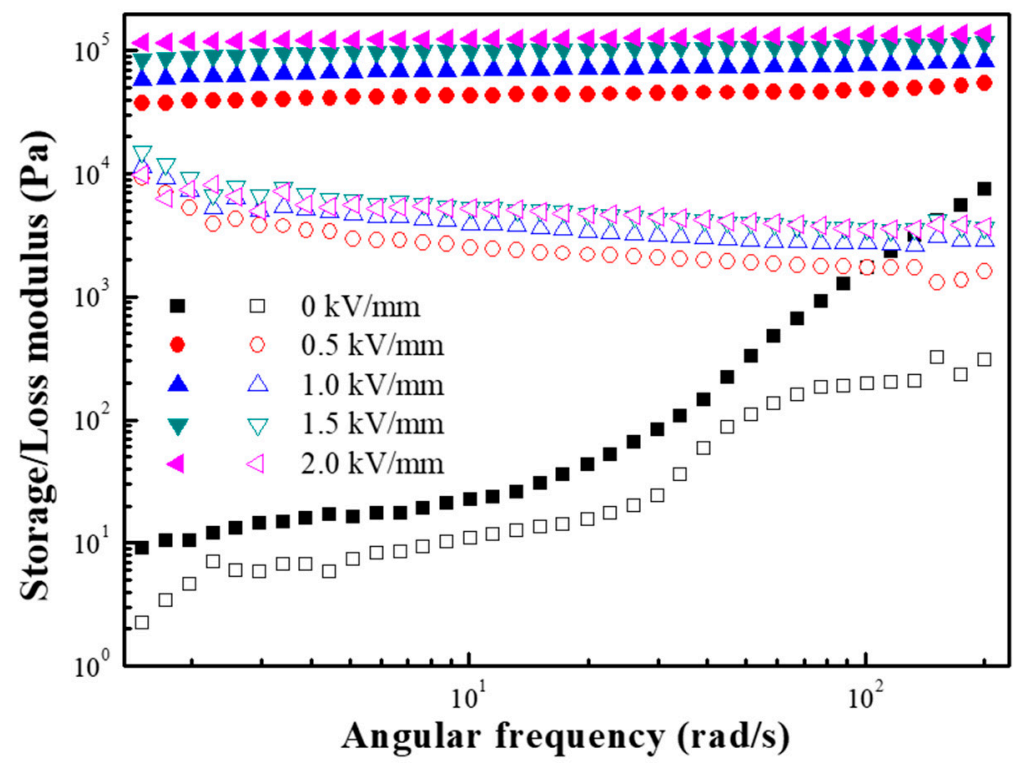

Figure 10. Storage ( $G^{\prime}$, closed symbols) and loss ( $G^{\prime \prime}$, open symbols) moduli as a function of angular frequency for PDPA/ $\mathrm{Fe}_{3} \mathrm{O}_{4}$-based ER fluid (10 vol\%, $50 \mathrm{cSt}$ silicone oil) with constant strain of $0.007 \%$. 


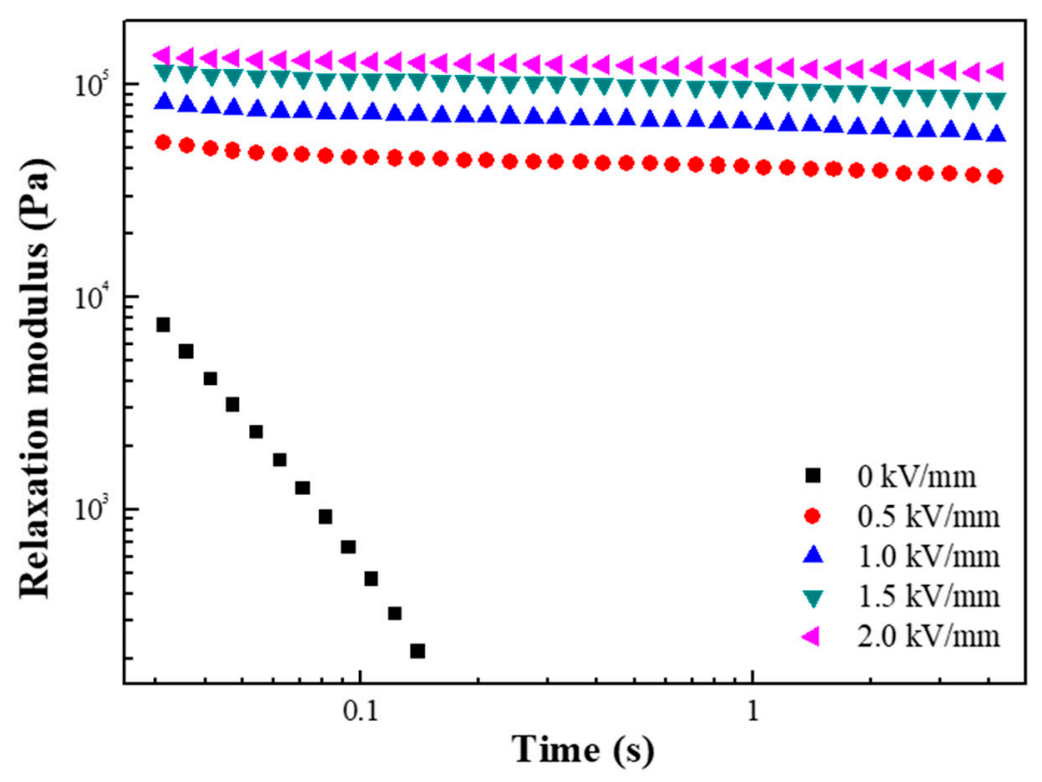

Figure 11. Time-dependent relaxation modulus of $\mathrm{PDPA} / \mathrm{Fe}_{3} \mathrm{O}_{4}$-based ER fluid $(10 \mathrm{vol} \%, 50 \mathrm{cSt}$ silicone oil).

\subsubsection{Dielectric Properties}

In addition, the frequency-dependent dielectric behaviors of the ER suspension are important for predicting its ER effects. To further study the relationship among them, the dielectric constant $\left(\varepsilon^{\prime}\right)$ and loss factor $\left(\varepsilon^{\prime \prime}\right)$ of the PDPA/ $\mathrm{Fe}_{3} \mathrm{O}_{4}$-based ER suspension over the wide frequency region (from 20 to $10^{6} \mathrm{~Hz}$ ) were tested using a LCR meter. Note that dielectric relaxation of materials can be described simply using the following Cole-Cole equation $[57,58]$

$$
\varepsilon^{*}=\varepsilon^{\prime}+i \varepsilon^{\prime \prime}=\varepsilon_{\infty}+\frac{\varepsilon_{0}-\varepsilon_{\infty}}{1+(i \omega \lambda)^{1-\alpha}} ; 0 \leq \alpha<1 .
$$

According to this equation, the dielectric constant $\left(\varepsilon^{\prime}\right)$ and loss factor $\left(\varepsilon^{\prime \prime}\right)$ can be expressed as

$$
\begin{gathered}
\varepsilon^{\prime}=\varepsilon_{\infty}+\left(\varepsilon_{0}-\varepsilon_{\infty}\right) \frac{1+(\omega \lambda)^{1-\alpha} \cos \frac{\pi(1-\alpha)}{2}}{1+2(\omega \lambda)^{1-\alpha} \cos \frac{\pi(1-\alpha)}{2}+(\omega \lambda)^{2(1-\alpha)}} \\
\varepsilon^{\prime \prime}=\frac{\left(\varepsilon_{0}-\varepsilon_{\infty}\right)(\omega \lambda)^{1-\alpha} \sin \frac{\pi(1-\alpha)}{2}}{1+2(\omega \lambda)^{1-\alpha} \sin \frac{\alpha \pi}{2}+(\omega \lambda)^{2(1-\alpha)}}
\end{gathered}
$$

where $\varepsilon *$ is the complex dielectric constant; $\varepsilon_{0}$ and $\varepsilon_{\infty}$ are the dielectric constants as the frequency approaches to zero and infinity, respectively; $\omega=2 \pi f, f$ is the frequency; $\lambda$ represents the polarization relaxation time; the exponent $\alpha$ takes a value between 0 and 1 , which can describe different polarization relaxation situations.

Figure 12 gives the dielectric values of the PDPA/ $\mathrm{Fe}_{3} \mathrm{O}_{4}$ ER fluid, in which the solid lines were fitted using Cole-Cole equation with their fitted parameters shown in Table 2. The value of $\Delta \varepsilon$ is related to the electrostatic interactive forces among the dispersed particles, which can be seen as the achievable polarizability of an ER suspension. The polarization relaxation time $(\lambda)$ reflects the ER effect, in which the faster relaxation time generally contributes to the higher yield stress enhancement [59]. The exponent $(1-\alpha)$ is associated with the distribution broadness of the polarization relaxation time, and when $\alpha=0$, it indicates a single relaxation time. As shown in Table 2, the $\Delta \varepsilon$ value of PDPA/ $/ \mathrm{Fe}_{3} \mathrm{O}_{4}$-based ER fluid was 3.07 and the relaxation time was fast enough to be $1.23 \times 10^{-5} \mathrm{~s}$, which indicated that the PDPA/ $\mathrm{Fe}_{3} \mathrm{O}_{4}$ ER suspension had high polarizability and high 
yield stresses enhancement, which requires further study. Moreover, the ER tests showed that the conclusions inferred by dielectric properties were consistent with the results of the ER experiments. Meanwhile, compared with the PDPA-based ER fluid $(\Delta \varepsilon=0.62)$ [43], the $\Delta \varepsilon$ value of the PDPA/ $\mathrm{Fe}_{3} \mathrm{O}_{4}$ ER suspension was significantly higher, which was consistent with the result of PDPA/ $/ \mathrm{Fe}_{3} \mathrm{O}_{4}$-based ER fluid exhibiting higher shear stress, shear viscosity, dynamic moduli, and ER efficiency than the PDPA-based ER suspension with an electrical field.

In addition, magnetorheological (MR) fluids have similar properties to ER suspensions, which are usually composed of soft-magnetic particles dispersed in a carrier liquid, and its viscoelastic properties change significantly with the employment and withdrawal of the magnetic field. Because the as-fabricated PDPA $/ \mathrm{Fe}_{3} \mathrm{O}_{4}$ is a soft magnetic material, it has also been studied as an MR material. The detailed contents can be found in previous work [60], where the PDPA/ $\mathrm{Fe}_{3} \mathrm{O}_{4}$-based MR fluid provided a largely increased shear stress, shear viscosity, and dynamic moduli with the application of a magnetic field.
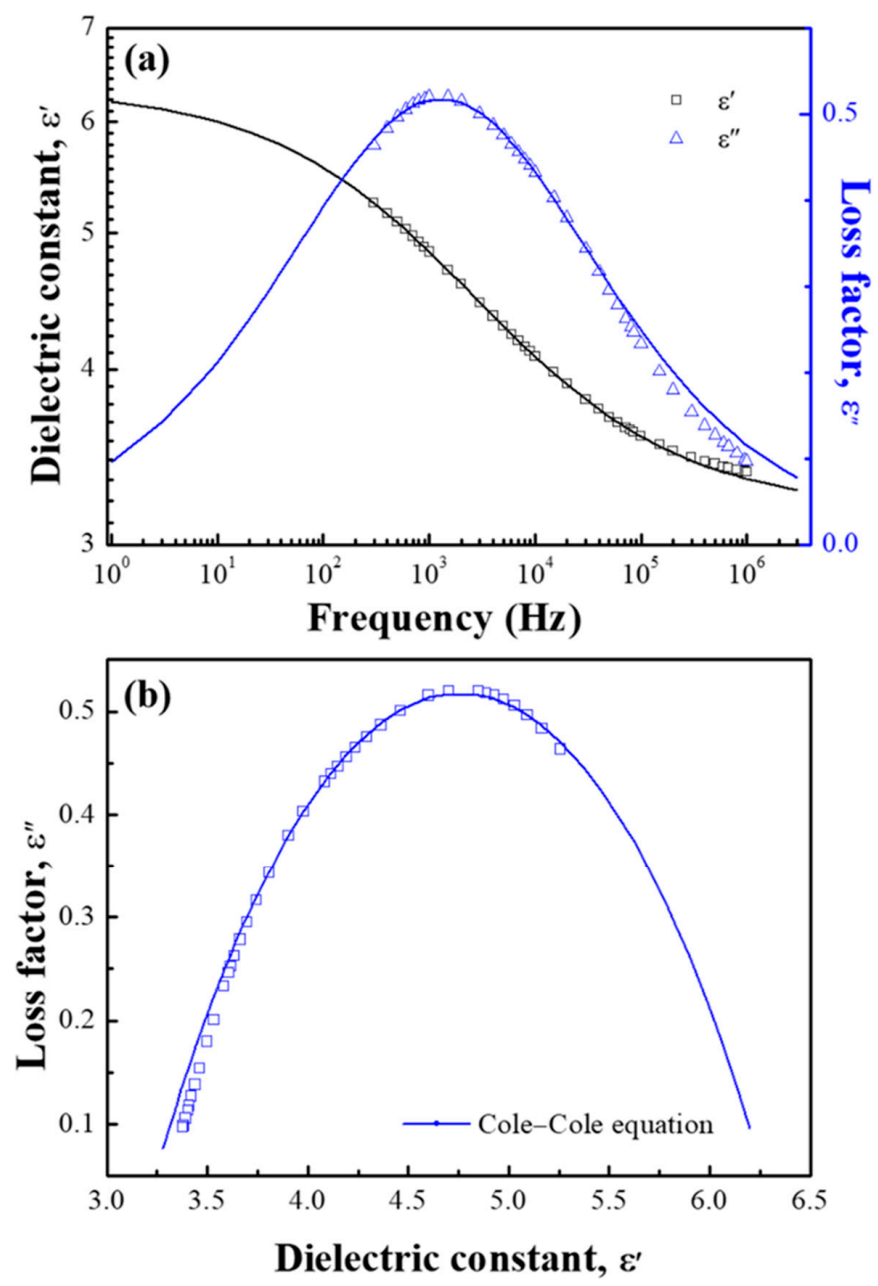

Figure 12. Dielectric properties: (a) dielectric constant (square) and loss factor (triangular) vs. frequency and (b) loss factor vs. dielectric constant for the PDPA/ $\mathrm{Fe}_{3} \mathrm{O}_{4}$-based ER fluid (10 vol\%, 50 cSt silicone oil). Solid lines were drawn from Cole-Cole equation.

Table 2. Fitted parameters of Cole-Cole equation for PDPA/ $/ \mathrm{Fe}_{3} \mathrm{O}_{4}$-based ER fluid $(10 \mathrm{vol} \%$, $50 \mathrm{cSt}$ silicone oil).

\begin{tabular}{cccccc}
\hline Parameters & $\varepsilon_{0}$ & $\varepsilon_{\infty}$ & $\Delta \varepsilon=\varepsilon_{0}-\varepsilon_{\infty}$ & $\lambda(\mathbf{s})$ & $\alpha$ \\
\hline Value & 6.34 & 3.17 & 3.07 & $1.23 \times 10^{-5}$ & 0.598 \\
\hline
\end{tabular}




\section{Conclusions}

Electro-responsive composite ( $\mathrm{PDPA} / \mathrm{Fe}_{3} \mathrm{O}_{4}$ ) particles were fabricated by synthesizing PDPA using an oxidation polymerization method and loading nano-sized $\mathrm{Fe}_{3} \mathrm{O}_{4}$ particles onto it using chemical co-precipitation. The morphology and crystal structure of the fabricated PDPA/ $/ \mathrm{Fe}_{3} \mathrm{O}_{4}$ was studied by SEM, TEM, and XRD. The formation of chain-like structures of PDPA/ $/ \mathrm{Fe}_{3} \mathrm{O}_{4}$ particles with an external electrical field was characterized by optical microscopy. The rheological characteristics of the $\mathrm{PDPA} / \mathrm{Fe}_{3} \mathrm{O}_{4}$ ER suspension under various electrical field strengths were investigated by a rotation rheometer. In the static shear tests, the PDPA/ $/ \mathrm{Fe}_{3} \mathrm{O}_{4}$-based ER fluid demonstrated a Newtonian fluid property, while under an electrical field, the ER suspension demonstrated Bingham plastic behavior and was fitted well by the Bingham model. In the dynamic oscillation tests, with an input electrical field, the dynamic moduli showed a dramatic increase and provided proof of the transition of the ER suspension from a liquid-like to solid-like state. The relationship between yield stresses and electrical field strength showed that it conforms to the conduction model. The dielectric characteristics of the $\mathrm{PDPA} / \mathrm{Fe}_{3} \mathrm{O}_{4}$ ER suspension also were tested via a LCR meter, corresponding to the ER characteristics. Furthermore, along with its MR characteristics previously reported, the PDPA $/ \mathrm{Fe}_{3} \mathrm{O}_{4}$-based ER fluid can contribute to more stable ER performance than a PDPA-based ER fluid. Compared with the other previously reported organic-inorganic ER materials, the most significant advantage of the $\mathrm{PDPA} / \mathrm{Fe}_{3} \mathrm{O}_{4}$ was that it had suitable conductivity, so that no de-doping step was needed, which undoubtedly improved the economic efficiency while simplifying the operation. All in all, the synthesis process of the PDPA itself was simple, the flow behavior of the PDPA/ $\mathrm{Fe}_{3} \mathrm{O}_{4}$ ER fluid was stable, the ER efficiency was high, and the economic benefit was good; these advantages of the PDPA/ $/ \mathrm{Fe}_{3} \mathrm{O}_{4}$ ER fluid are beneficial to its application in engineering.

Author Contributions: Conceptualization, Y.Z.D. and H.J.C.; writing-original draft preparation, Y.Z.D.; writing-review and editing, H.J.C.; Funding Acquisition, H.J.C.

Funding: This research was funded by the National Research Foundation of Korea (2018R1A4A1025169).

Conflicts of Interest: The authors declare that they have no conflict of interest.

\section{References}

1. Cabuk, M.; Yavuz, M.; Unal, H.I. Electrokinetic, electrorheological and viscoelastic properties of Polythiophene-graft-Chitosan copolymer particles. Colloids Surf. A Physicochem. Eng. Asp. 2016, 510, 231-238. [CrossRef]

2. Sheng, P.; Wen, W. Electrorheological Fluids: Mechanisms, Dynamics, and Microfluidics Applications. J. Fluid Mech. 2011, 44, 143-174. [CrossRef]

3. Kontopoulou, M.; Kaufman, M.; Docoslis, A. Electrorheological properties of PDMS/carbon black suspensions under shear flow. Rheol. Acta 2009, 48, 409-421. [CrossRef]

4. Plachy, T.; Sedlacik, M.; Pavlinek, V.; Moravkova, Z.; Hajna, M.; Stejskal, J. An effect of carbonization on the electrorheology of poly(p-phenylenediamine). Carbon 2013, 63, 187-195. [CrossRef]

5. Liu, J.; Wen, X.; Liu, Z.; Tan, Y.; Yang, S.; Zhang, P. Electrorheological performances of poly(o-toluidine) and p-toluenesulfonic acid doped poly(o-toluidine) suspensions. Colloid Polym. Sci. 2015, 293, 1391-1400. [CrossRef]

6. Yin, J.; Chang, R.; Shui, Y.; Zhao, X. Preparation and enhanced electro-responsive characteristic of reduced graphene oxide/polypyrrole composite sheet suspensions. Soft Matter 2013, 9, 7468-7478. [CrossRef]

7. Mrlik, M.; Ilcikova, M.; Plachy, T.; Moucka, R.; Pavlinek, V.; Mosnacek, J. Tunable electrorheological performance of silicone oil suspensions based on controllably reduced graphene oxide by surface initiated atom transfer radical polymerization of poly(glycidyl methacrylate). J. Ind. Eng. Chem. 2018, 57, $104-112$. [CrossRef]

8. Bauerochs, T.; Ulrich, S.; Schneider, S.; Bruns, R. Approach on the improvement of the durability of an electrorheological valve. J. Intell. Mater. Syst. Struct. 2018, 29, 3737-3747. [CrossRef]

9. Chiolerio, A.; Quadrelli, M.B. Smart fluid systems: The advent of autonomous liquid robotics. Adv. Sci. 2017, 4, 1700036. [CrossRef] [PubMed] 
10. Bansevicius, R.; Virbalis, J. Two-dimensional Braille readers based on electrorheological fluid valves controlled by electric field. Mechatronics 2007, 17, 570-577. [CrossRef]

11. Rodionova, G.; Sjoblom, J. Electrorheological Behavior of Crude Oil and Synthetic Reference Fluid Emulsions. J. Dispers. Sci. Technol. 2015, 36, 1388-1393. [CrossRef]

12. Tao, R.; Tang, H.; Tawhid-Al-Islam, K.; Du, E.; Kim, J. Electrorheology leads to healthier and tastier chocolate. Proc. Natl. Acad. Sci. USA 2016, 113, 7399-7402. [CrossRef] [PubMed]

13. Sim, B.; Bae, D.H.; Choi, H.J.; Choi, K.; Islam, M.S.; Kao, N. Fabrication and stimuli response of rice husk-based microcrystalline cellulose particle suspension under electric fields. Cellulose 2016, 23, 185-197. [CrossRef]

14. Lee, I.S.; Lee, J.Y.; Sung, J.H.; Choi, H.J. Synthesis and electrorheological characteristics of polyaniline-titanium dioxide hybrid suspension. Synth. Met. 2005, 152, 173-176. [CrossRef]

15. Parmar, K.; Méheust, Y.; Schjelderupsen, B.; Fossum, J.O. Electrorheological suspensions of laponite in oil: Rheometry studies. Langmuir 2008, 24, 1814-1822. [CrossRef]

16. Wen, Q.; Ma, L.; Wang, C.; Wang, B.; Han, R.; Hao, C.; Chen, K. Preparation of core-shell structured metal-organic framework@PANI nanocomposite and its electrorheological properties. RSC Adv. 2019, 9, 14520-14530. [CrossRef]

17. Kim, J.W.; Liu, F.; Choi, H.J. Polypyrrole/clay nanocomposite and its electrorheological characteristics. J. Ind. Eng. Chem. 2002, 8, 399-403.

18. Zhang, W.L.; Liu, Y.D.; Choi, H.J.; Kim, S.G. Electrorheology of Graphene Oxide. ACS Appl. Mater. Interf. 2012, 4, 2267-2272. [CrossRef]

19. Dong, Y.Z.; Yin, J.; Zhao, X. Microwave-synthesized poly(ionic liquid) particles: A new material with high electrorheological activity. J. Mater. Chem. A 2014, 2, 9812-9819. [CrossRef]

20. Hakimian, A.; Nateghi, M.R. Oxidation kinetics and conformational relaxation of poly (N-methylaniline) in aqueous solution. Synth. Met. 2015, 202,1-7. [CrossRef]

21. Abdiryim, T.; Zhang, X.G.; Jamal, R. Comparative studies of solid-state synthesized polyaniline doped with inorganic acids. Mater. Chem. Phys. 2005, 90, 367-372. [CrossRef]

22. He, K.; Qin, C.; Wen, Q.; Wang, C.; Wang, B.; Yu, S.; Hao, C.; Chen, K. Facile fabrication of polyaniline/polypyrrole copolymer nanofibers with a rough surface and their electrorheological activities. J. Appl. Polym. Sci. 2018, 135, 46289. [CrossRef]

23. Chotpattananont, D.; Sirivat, A.; Jamieson, A.M. Creep and recovery behaviors of a polythiophene-based electrorheological fluid. Polymer 2006, 47, 3568-3575. [CrossRef]

24. Fang, F.F.; Dong, Y.Z.; Choi, H.J. Effect of oxidants on morphology of interfacial polymerized polyaniline nanofibers and their electrorheological response. Polymer 2018, 158, 176-182. [CrossRef]

25. Wu, S.; Zeng, F.; Shen, J. The electrorheological properties of polypyrrole suspensions. Polym. J. 1998, 30, 451-454. [CrossRef]

26. Jang, W.H.; Kim, J.W.; Choi, H.J.; Jhon, M.S. Synthesis and electrorheology of camphorsulfonic acid doped polyaniline suspensions. Colloid Polym. Sci. 2001, 279, 823-827. [CrossRef]

27. Showkat, A.M.; Lee, K.-P.; Gopalan, A.I.; Kim, S.-H. Synthesis and chiro-optical properties of water processable conducting poly(diphenylamine) nanocomposites. Macromol. Res. 2007, 15, 575-580. [CrossRef]

28. Liu, Y.D.; Choi, H.J. Electrorheological response of polyaniline and its hybrids. Chem. Paper 2013, 67, 849-859. [CrossRef]

29. Lu, Q.; Han, W.J.; Choi, H.J. Smart and Functional Conducting Polymers: Application to Electrorheological Fluids. Molecules 2018, 23, 2854. [CrossRef]

30. Kim, J.W.; Kim, S.G.; Choi, H.J.; Suh, M.S.; Shin, M.J.; Jhon, M.S. Synthesis and electrorheological characterization of polyaniline and $\mathrm{Na}$-montmorillonite clay nanocomposite. Int. J. Mod. Phys. B 2001, 15, 657-664. [CrossRef]

31. Jun, C.S.; Sim, B.; Choi, H.J. Fabrication of electric-stimuli responsive polyaniline/laponite composite and its viscoelastic and dielectric characteristics. Colloids Surf. A 2015, 482, 670-677. [CrossRef]

32. Park, D.E.; Dong, Y.Z.; Choi, H.J. Fabrication and electric stimuli-response of semiconducting poly(3,4-ethylenedioxythiophene)/silica nanocomposite particles. Eur. Polym. J. 2018, 101, 255-261. [CrossRef]

33. Park, D.E.; Chae, H.S.; Choi, H.J.; Maity, A. Magnetite-polypyrrole core-shell structured microspheres and their dual stimuli-response under electric and magnetic fields. J. Mater. Chem. C 2015, 3, 3150-3158. [CrossRef] 
34. Kim, M.W.; Moon, I.J.; Choi, H.J.; Seo, Y. Facile fabrication of core/shell structured $\mathrm{SiO}_{2} / \mathrm{polypyrrole}$ nanoparticles with surface modification and their electrorheology. RSC Adv. 2016, 6, 56495-56502. [CrossRef]

35. Tian, X.; He, K.; Wang, B.; Yu, S.; Hao, C.; Chen, K.; Lei, Q. Flower-like $\mathrm{Fe}_{2} \mathrm{O}_{3} /$ polyaniline core/shell nanocomposite and its electroheological properties. Colloids Surf. A 2016, 498, 185-193. [CrossRef]

36. Wang, B.; Liu, C.; Yin, Y.; Yu, S.; Chen, K.; Liu, P.; Liang, B. Double template assisting synthesized core-shell structured titania/polyaniline nanocomposite and its smart electrorheological response. Compos. Sci. Tech. 2013, 86, 89-100. [CrossRef]

37. Cheng, Q.; Pavlinek, V.; He, Y.; Li, C.; Saha, P. Electrorheological characteristics of polyaniline/titanate composite nanotube suspensions. Colloid Polym. Sci. 2009, 287, 435-441. [CrossRef]

38. Sim, B.; Chae, H.S.; Choi, H.J. Fabrication of polyaniline coated iron oxide hybrid particles and their dual stimuli-response under electric and magnetic fields. Express Polym. Lett. 2015, 9, 736-743. [CrossRef]

39. Nami, N.; Tajbakhsh, M.; Vafakhah, M. Application and comparison of the catalytic activity of $\mathrm{Fe}_{3} \mathrm{O}_{4} \mathrm{MNPs}_{\text {, }}$ Kaolin and Montmorillonite K10 for the synthesis of indole derivatives. Iranian Chem. Commun. 2019, 7, 1-12.

40. Xian, Y.; Wu, Y.; Dong, H.; Chen, L.; Zhang, C.; Hou, X.; Zeng, X.; Bai, W.; Guo, X. Modified QuEChERS purification and $\mathrm{Fe}_{3} \mathrm{O}_{4}$ nanoparticle decoloration for robust analysis of 14 heterocyclic aromatic amines and acrylamide in coffee products using UHPLC-MS/MS. Food Chem. 2019, 285, 77-85. [CrossRef]

41. Rahmatinia, Z.; Rahmatinia, M. Removal of the metronidazole from aqueous solution by heterogeneous electro-Fenton process using nano- $\mathrm{Fe}_{3} \mathrm{O}_{4}$. Data Br. 2018, 19, 2139-2145. [CrossRef] [PubMed]

42. Lu, J.B.; Yan, Q.S.; Tian, H.; Kong, L.Y. Polishing properties of tiny grinding wheel based on $\mathrm{Fe}_{3} \mathrm{O}_{4}$ electrorheological fluid. J. Mater. Process. Tech. 2009, 209, 4954-4957. [CrossRef]

43. Kim, M.H.; Bae, D.H.; Choi, H.J.; Seo, Y. Synthesis of semiconducting poly (diphenylamine) particles and analysis of their electrorheological properties. Polymer 2017, 119, 40-49. [CrossRef]

44. Patterson, A. The Scherrer formula for X-ray particle size determination. Phys. Rev. 1939, 56, 978-982. [CrossRef]

45. Wang, Z.; Lin, Z.; Fang, H.; Tao, R. Dynamic response times of electrorheological fluids in steady shear. J. Appl. Phys. 1998, 83, 1125-1131. [CrossRef]

46. Martin, J.E.; Odinek, J. Aggregation, Fragmentation, and Nonlinear Dynamics of Electrorheological Fluids in Oscillatory Shear. Phys. Rev. Lett. 1995, 75, 2827-2830. [CrossRef] [PubMed]

47. Belijar, G.; Valdez-Nava, Z.; Diaham, S.; Laudebat, L.; Jones, T.B.; Lebey, T. Dynamics of particle chain formation in a liquid polymer under ac electric field: Modeling and experiments. J. Phys. D Appl. Phys. 2017, 50, 025303. [CrossRef]

48. Stolyarova, D.Y.; Kuznetsov, N.M.; Belousov, S.I.; Chvalun, S.N. Electrorheological behavior of low filled suspensions of highly anisometric montmorillonite particles. J. Appl. Polym. Sci. 2019, 136, 47678. [CrossRef]

49. Murphy, E.; Lomboy, G.; Wang, K.; Sundararajan, S.; Subramaniam, S. The rheology of slurries of athermal cohesive micro-particles immersed in fluid: A computational and experimental comparison. Chem. Eng. Sci. 2019, 193, 411-420. [CrossRef]

50. Cho, M.S.; Choi, H.J.; Jhon, M.S. Shear stress analysis of a semiconducting polymer based electrorheological fluid system. Polymer 2005, 46, 11484-11488. [CrossRef]

51. Marins, J.A.; Giulieri, F.; Soares, B.G.; Bossis, G. Hybrid polyaniline-coated sepiolite nanofibers for electrorheological fluid applications. Synth. Met. 2013, 185, 9-16. [CrossRef]

52. Walls, H.J.; Caines, S.B.; Sanchez, A.M.; Khan, S.A. Yield stress and wall slip phenomena in colloidal silica gels. J. Rheol. 2003, 47, 847-868. [CrossRef]

53. Castro, M.; Giles, D.W.; Macosko, C.W.; Moaddel, T. Comparison of methods to measure yield stress of soft solids. J. Rheol. 2010, 54, 81-94. [CrossRef]

54. De Vicente, J.; Klingenberg, D.J.; Hidalgo-Alvarez, R. Magnetorheological fluids: A review. Soft Matter 2011, 7, 3701-3710. [CrossRef]

55. Davis, L.; Ginder, J. Electrostatic Forces in Electrorheological Fluids. In Progress in Electrorheology; Springer: Boston, MA, USA, 1995; pp. 107-114.

56. Emri, I.; von Bernstorff, B.S.; Cvelbar, R.; Nikonov, A. Re-examination of the approximate methods for interconversion between frequency- and time-dependent material functions. J. Nonnewton. Fluid Mech. 2005, 129, 75-84. [CrossRef]

57. Cole, K.S.; Cole, R.H. Dispersion and absorption in dielectrics I. Alternating current characteristics. J. Chem. Phys. 1941, 9, 341-351. [CrossRef] 
58. Park, I.H.; Kwon, S.H.; Choi, H.J. Emulsion-polymerized polyindole nanoparticles and their electrorheology. J. Appl. Polym. Sci. 2018, 135, 46384. [CrossRef]

59. Plachy, T.; Sedlacik, M.; Pavlínek, V.; Stejskal, J. The observation of a conductivity threshold on the electrorheological effect of p-phenylenediamine oxidized with p-benzoquinone. J. Mater. Chem. C 2015, 3, 9973-9980. [CrossRef]

60. Dong, Y.Z.; Choi, H.J. Synthesis of organic-inorganic poly(diphenylamine)/magnetite composite particles and their magnetorheological response. IEEE Trans. Magn. 2018, 54, 4601004. [CrossRef]

(C) 2019 by the authors. Licensee MDPI, Basel, Switzerland. This article is an open access article distributed under the terms and conditions of the Creative Commons Attribution (CC BY) license (http://creativecommons.org/licenses/by/4.0/). 